Editorial

\title{
Biominerals: Formation, Function, Properties
}

\author{
Helmut Cölfen ${ }^{1, *(\mathbb{D}}$, Erika Griesshaber ${ }^{2}$ and Wolfgang W. Schmahl ${ }^{2}$ \\ 1 Physical Chemistry, Universität Konstanz, 78457 Konstanz, Germany \\ 2 Department of Earth and Environmental Sciences, 80333 Munich, Germany; \\ Wolfgang.W.Schmahl@lrz.uni-muenchen.de (W.W.S.); e.griesshaber@lrz.uni-muenchen.de (E.G.) \\ * Correspondence: helmut.coelfen@uni-konstanz.de
}

Citation: Cölfen, H.; Griesshaber, E.; Schmahl, W.W. Biominerals:

Formation, Function, Properties.

Crystals 2021, 11, 299. https://

doi.org/10.3390/cryst11030299

Received: 23 February 2021

Accepted: 11 March 2021

Published: 17 March 2021

Publisher's Note: MDPI stays neutral with regard to jurisdictional claims in published maps and institutional affiliations.

Copyright: (C) 2021 by the authors. Licensee MDPI, Basel, Switzerland. This article is an open access article distributed under the terms and conditions of the Creative Commons Attribution (CC BY) license (https:/ / creativecommons.org/licenses/by/ $4.0 /)$.
Triggered by geochemical cycles, large-scale terrestrial processes and evolution, a tremendous biodiversity evolved over the geological record and produced proto- and metazoa with biomineralized hard tissue, characterized by unique structural designs and exquisite performance. These extraordinary structures and properties are a result of the precise control of the mineralization process by the living organism. This is directed by biomolecules forming a structural insoluble matrix acting as a scaffold for the mineral and soluble functional biomolecules, which can control the nucleation and mineralization process itself, sometimes starting before nucleation of the mineral by ion accumulation. The constructive process of the secretion of biopolymer and biomineral components is guided by the metabolic activity of cells. Organisms interact closely with the biologic and inorganic realms of their environment and generate composite materials for protection and survival. This implies the adaptation of biomaterial functionality to lifestyle and ecosystems. The diversity of biomineral architectures is linked to the evolution of life in different and episodically changing climates and environments, and it thus directly reflects catastrophic events in the Earth's history. Biomineralized materials are also key components in technologies ranging from regenerative medicine, tissue engineering and prosthetics to material manufacturing.

Biomineralized tissue has initiated important developments for terrestrial environments. It provided the impetus for the formation of silica, phosphate and carbonate sediment deposits. Many theories have been put forward to explain why biomineralization occurred in the geologic record at all. Biomineralization could have been the consequence of: (i) the removal of toxic levels of intracellular $\mathrm{Ca}^{2+}$; (ii) the release of ions triggered by physical/chemical weathering of continents; (iii) defense against increasing predation pressure. Whatever the controlling process of biomineralization was, the result was the development of single- and multicellular organisms. These affected population dynamics and ecosystems by increasing the selective pressure on advantages gained from the fabrication of biological hard tissues, such as skeletons, shells, spines, teeth, gravity-sensing organs, eye lenses, mineral storage units.

Research in biomineralization is, by definition, highly multidisciplinary, as it needs to draw on expertise from Biology, Earth Sciences, Chemistry, Medicine, Material Science, Physics and Engineering. Progress in the field is rooted in the tight collaboration between many and diverse scientific disciplines, investigation of a wide range of biological metabolites and a two-way transfer of knowledge between biological and bioinspired systems. BIOMIN conferences, a series of biannually organized International Meetings on Biomineralization, provides the required forum for intense multidisciplinary exchange on recent advances and open questions. The 15th International Symposium on Biomineralization, BIOMIN XV, held in Munich, Germany, from 9 to 13 September 2019, welcomed 236 participants from 30 countries worldwide. The Symposium covered 205 scientific contributions: 8 keynote lectures, and 89 oral and 108 poster presentations. BIOMIN XV was organized into nine sessions: (i) biomineral transport, deposition and organization; (ii) bioinspired crystallization; (iii) Biomineralization of echinoderms and sponges; (iv) Biomineralization 
of plants and protoctistans; (v) phosphates: teeth and bones; (vi) from corals to molecular biological techniques in Biomineralization; (vii) microbial activity in Biomineralization; (viii) Biomineralization and environment; (ix) evolution of skeletal Biomineralization.

The idea for this thematic issue originated from the organization of BIOMIN XV. This thematic issue, published in Crystals, focuses on a wide range of topics in the realm of biological and biomimetic mineralization. The Special Issue 'Biominerals: Formation, Function, Properties' is a collection of eight articles, a review and seven research articles.

The review of Kato and Suzuki [1] describes the processes of metal and metal chalcogenide nanoparticle generation by microorganisms. These nanoparticles are functional organic-inorganic biomarkers and are of major importance for medical applications. Bacteria and fungi are able to synthesise, intra- and/or extracellularly, a wide range of metal nanoparticles, such as: $\mathrm{Ag}, \mathrm{Au}, \mathrm{CdS}, \mathrm{CdSe}, \mathrm{Cu}, \mathrm{CuO}, \mathrm{Pt}, \mathrm{Pb}, \mathrm{Ti}, \mathrm{TiO}_{2}$. The study shows that genetical control mechanisms of bacteria and fungi regulate the size and shape of the nanoparticles as well as the number of nanoparticles secreted by the microorganisms. The interaction of bacteria with substrate surfaces, marble [2] and copper sulphide [3] is detailed by Sazanova et al. [2] and Varotsis et al. [3]. Sazanova et al. investigate the degree of carbonate and oxalate crystal formation by Bacillus subtilis and Aspergillus niger. The obtained results demonstrate that mineral secretion activity differs significantly for $B$. subtilis monocultures and $B$. subtilis $-A$. niger associations. The monoculture secretes less mineral, in contrast to the bacterial association. Furthermore, the study has shown that the phase composition and morphology of the precipitated crystals is influenced by the ratio of bacterial EPS-oxalic acid concentration in the growth medium. Bacterial cell attachment to copper sulphide surfaces was investigated by Varotsis et al. [3]. The research documented that the degree of CuS surface colonization by Acidithiobacillus ferrooxidans is mainly dependent on the speciation of the protein within the EPS, followed by nucleic acids and lipids.

The characterization of biological apatite is the focus of the contributions of Foley et al. [4], Dittfeld et al. [5] and Korneev et al. [6]. Foley et al. investigated, in a suite of 18 archeological human bone samples, the dependence between crystallographic lattice parameters and bone function, physicality and bone chemical composition [4]. The authors demonstrate systematic variation differences in a- and c-unit cell edge-length with relative bioapatite chemical composition and crystallite size, but not with bone mechanical function and, thus, the position of the bone in the human body. Dittfeld et al. could show that, in contrast to results obtained with von Kossa staining techniques, multivariate evaluation of FT-IR spectroscopical data allows for the differentiation between mineralized and nonmineralized human aortic valve tissue [5]. Accordingly, the developed analytical tool (measurements and specific data evaluation) enables the identification of extracellular matrix modification and remodelling when the aortic valve is mineralized pathologically. The influence of fluorine on the formation of human oxalate and phosphate kidney stones was studied by Korneev et al. [6]. It is demonstrated that oxalate kidney stones contained fluorine, while pure phosphatic kidney stones were devoid of fluorine. It is further shown that an increase in fluorine content resulted in an increase in oxalate mineral content, as well as an increase in the a-unit cell parameter of apatite crystallites. Korneev et al. suggest that fluorapatite is a more suitable precursor for the formation of oxalates of kidney stones, in comparison to hydroxylapatite. This is based on the fact that fluorine-bearing apatite forms at a lower $\mathrm{pH}$ in comparison to hydroxylapatite.

Biocarbonate mineralization is the focus of research described by Oudot et al. [7] and Mishima et al. [8]. The calcitic shell of Argonauta hians was sampled for biochemical characterization of the extracellular organic matrix present in the shell [7]. The results show that the latter consists of unusual proportions of soluble and insoluble components and consists mainly of proteins complemented with a low amount of sulphated glycosaminoglycans. Proteomic analysis performed on Argonauta hians calcite identified peptide sequences and some proteins that are not shared with other molluscan shell matrices. These differences in extracellular matrix composition, relative to those observed for molluscs, pose implications 
for the evolution of cephalopod shell matrices. The relationship between the habitat, periodicity and regularity of incremental lines of fossil fish otoliths is highlighted and discussed by Mishima et al. [8]. Based on a suite of analytical techniques, the authors demonstrated that those fish species that live mainly in waters of the continental slope develop a regular array of cicardian incremental lines. However, species that spend the day in deep- and the night in shallow-water environments develop disturbed arrays of incremental lines. The authors postulate that seawater temperature and pressure fluctuations significantly influence the regularity and clarity of fish otolith incremental lines.

Conflicts of Interest: The authors declare no conflict of interest.

\section{References}

1. Kato, Y.; Suzuki, M. Synthesis of metal nanoparticles by microorganisms. Crystals 2020, 10, 589. [CrossRef]

2. Sazanova, K.V.; Frank-Kamenetskaya, O.V.; Vlasov, D.Y.; Zelenskaya, M.S.; Vlasov, A.D.; Rusakov, A.V.; Petrova, M.A. Carbonate and oxalate crystallization by interaction of calcite marble with Bacillus subtilis and Bacillus subtilis-Aspergillus niger association. Crystals 2020, 10, 756. [CrossRef]

3. Varotsis, C.; Papageorgiou, M.; Tselios, C.; Yiannakkos, K.A.; Adamou, A.; Nicolaides, A. Bacterial colonization on the surface of copper sulphide minerals probed by Fourier transform infrared micro-spectroscopy. Crystals 2020, 10, 1002. [CrossRef]

4. Foley, B.; Greiner, M.; McGlynn, G.; Schmahl, W.W. Anatomical variation of human bone bioapatite crystallography. Crystals 2020, 10, 859. [CrossRef]

5. Dittfeld, C.; Mieting, A.; Welzel, C.; Jannasch, A.; Matschke, K.; Tugtekin, S.-M.; Steiner, G. Molecular spectroscopic imaging offers a systematic assessment of pathological aortic valve and prothesis tissue in biomineralization. Crystals 2020, 10, 763. [CrossRef]

6. Korneev, A.V.; Frank-Kamenskaya, O.V.; Izatulina, A.R. About the role of fluorine-bearing apatite in the formation of oxalate kidney stones. Crystals 2020, 10, 486. [CrossRef]

7. Oudot, M.; Shir, I.B.; Schmidt, A.; Plasseraud, L.; Broussard, C.; Neige, P.; Marin, F. A nature's curiosity: The Argonaut shell and its organic content. Crystals 2020, 10, 839. [CrossRef]

8. Mishima, H.; Kendo, Y.; Ohe, F.; Miake, Y.; Hayakawa, T. Relation between fish habitat and the periodicity of incremental lines in fossil otoliths. Crystals 2020, 10, 820. [CrossRef] 